\title{
The impact of animal source food products on human nutrition and health
}

\author{
H.C. Schönfeldt ${ }^{\#}$, B. Pretorius \& N. Hall \\ Associates of the Institute of Food, Nutrition and Well-being, University of Pretoria, Pretoria 0002, South Africa \\ Department of Animal and Wildlife Sciences, University of Pretoria, Pretoria 0002, South Africa
}

\begin{tabular}{c} 
Copyright resides with the authors in terms of the Creative Commons Attribution 2.5 South African Licence. \\
See: http://creativecommons.org/licenses/by/2.5/za \\
$\begin{array}{c}\text { Condition of use: The user may copy, distribute, transmit and adapt the work, but must recognise the authors and the South African Journal of Animal } \\
\text { Science }\end{array}$ \\
\hline
\end{tabular}

\begin{abstract}
Throughout the ages the quest for food and drink has influenced humanity's economic, social and political development, and played a role in the organization of society and history. Nutrition (or what we choose to consume) influences the health of human beings and therefore their quality of life. Animal source foods are often the dietary component that evokes the widest array of complex scientific, economic, environmental and political issues. It is viewed as the most expensive component of any diet, yet can make significant contributions to human health through providing high quantities of essential nutrients. In addition to quantity, the high quality of the nutrients in animal source foods is important as high-quality nutrients are more readily absorbed into the human body than lower-quality nutrients from other food and non-food sources. As South Africans increasingly suffer the consequences of inappropriate diets (over- and undernutrition), the role of animal source foods as part of a healthy diet requires continuous investment in research and extrapolation of information towards appropriate guidelines and recommendations. Although it is often suggested that the intake of animal source foods should be limited because of possible linkages between animal product consumption and health, scientific evidence increasingly indicates the beneficial role that animal source foods can play in preventing and combating obesity and certain non-communicable diseases related to over-nutrition. This article aims to describe the nutritional role of animal source foods as part of a healthy South African diet and presents a review of recent findings related to their nutrient contribution, as well as evidence relating to common health concerns.
\end{abstract}

Keywords: Animal source foods, livestock products, nutrition, health

\# Corresponding author: hettie.schonfeldt@up.ac.za

\section{Introduction}

Contributions to the diet by products from livestock such as cattle, sheep, goats, pigs, chickens, and lesser-known species can be beneficial or harmful to overall human health. In appropriate amounts, animal source foods are valuable sources of complete, high-quality, easily digestible protein and many essential micronutrients such as iron, zinc, calcium, vitamin $\mathrm{A}$ and vitamin $\mathrm{B}_{12}$. On the other side of the malnutrition scale, the overconsumption of certain foods, particularly those high in saturated fat and cholesterol, salt (sodium) and total energy, has been linked to overweight, obesity and subsequent diseases of lifestyle (WHO, 2007).

To maintain a healthy balance, a diet containing a diversity of foods from all the food groups is recommended, including starchy foods and cereals, vegetables and fruit, dairy products, meat and meat alternatives, as well as fats and sugars in minimal quantities.

The rapid increase in overweight and obesity, amid persistent nutritional deficiencies, has increased the focus on dietary choices. Animal source foods are often the subject of this debate, because of the potential of animal source foods to be nutrient dense (defined as a high ratio of nutrients (in grams) compared to the total energy content (in kilojoules) of a specific food product), and the possibility that certain animal source food options could be considered high in fat, saturated fat and total energy.

To highlight the severity of nutritional imbalances (owing to over- and under-nutrition) in South Africa, five of the top 10 risk factors for death are related directly to dietary choice, overweight and obesity, 
namely high blood pressure, excess body weight, high cholesterol, diabetes and physical inactivity. In comparison with the significant burden that overweight and obesity has on South Africans, childhood and maternal underweight are ranked as the 12th greatest risk factor for death, with vitamin A deficiency 14th and iron deficiency anaemia 16th (Norman et al., 2007). In this article the role of animal source foods in health concerns related to under-nutrition and over-nutrition are discussed.

\section{Undernutrition, related health risks and the role of animal source foods}

The global fight against hunger is well recognised, and ample policies are in place to increase food availability and access. Yet the provision of energy without adequate intake of critical nutrients such as protein and micronutrients may increase body weight, but not height. This may promote adipose tissue gain and obesity, without contributing to other dietary needs such as proteins and micronutrients. This may add to the prevalence of stunting and obesity in a single individual (Uauy \& Kain, 2002), which is increasingly observed in South Africa (NFCS-FB-I, 2008; SANHANES-1, 2013b). An insufficient supply of nutrients to the human body restricts and retards physical and cognitive development, and both manifest as financial and social burdens on society. The United Nations Standing Committee on Nutrition concluded that nutrition is an essential foundation for poverty alleviation, and good nutrition is essential to meeting the Millennium Development Goals (MDGs) of achieving universal education, promoting gender equality, reducing child mortality, improving maternal health and combating disease (FAO, 2004).

\section{Under-nutrition in South Africa}

In South Africa, stunting in children (which indicates severe micronutrient deficiencies during the growing years) is a significant concern. Stunting is a risk factor for increased mortality, poor cognitive and motor development, and other impairments in function. It usually persists into adulthood, resulting in smaller body size and lower work performance (Iversen et al., 2011). In 1994 stunting in children (6 to 71 months) was recorded as 22.9\% (SAVACG, 1996). In 1999 stunting was recorded as 21.6\% (NFCS, 1999). By 2005, after the mandatory fortification of staple foods had been implemented, $18 \%$ of children were still recorded as being stunted (NFCS-FB-I, 2008). Compared with the previous national survey in 2005, the South African National Health and Nutrition Examination Survey (SANHANES) in 2012 indicated a slight increase in stunting (26.5\%), but a clear decrease in wasting (extreme low weight for age) (2.2\%) and underweight (6.1\%) among children under three years. In the global context, the prevalence level may be classified as being of medium severity for stunting and low for wasting and underweight (SANHANES-1, 2013a).

Micronutrients of concern, which contribute to the incidence of stunting, include vitamin A, iron and zinc. Despite the mandatory fortification of staple foods with a mix of vitamin A, B vitamins, zinc and iron in October 2003, the National Food Consumption Survey (NFCS) in 2005 found persistent nutritional deficiencies in children and women. More than $60 \%$ of children and nearly $30 \%$ of women had vitamin A deficiency; nearly $30 \%$ of children and women had anaemia; and more than $45 \%$ of children had zinc deficiency (NFCS- FB-I, 2008). When the SANHANES-1 findings were compared with those of the 2005 NFCS, it was shown that the prevalence of anaemia and iron deficiency anaemia had decreased by $63 \%$ and $83.2 \%$, respectively. At national level, the prevalence of vitamin A deficiency was $43.6 \%$, which is a decrease from the 2005 reported prevalence (63.6\%) (SANHANES-1, 2013a). Although a decrease is observed, the data still motivate the need to promote multiple approaches. A food-based approach, as well as fortification of staple foods and supplementation is advised, as supplementation alone has not been successful in eliminating specific nutrition deficiencies.

Although studies indicate that food insecurity threatens a significant proportion of households and nutritional deficiencies continue to exist, increased incidence of overweight and obesity is reported in the same communities. This co-occurrence of nutritional problems suggests the consequences of a monotonous diet that is high in energy, but low in variety and essential nutrients such as proteins, vitamins and minerals. This seems to be a feasible hypothesis when seen against the backdrop that the five most commonly consumed foods in South Africa are maize meal, brown bread, sugar, tea and small amounts of whole milk (NFCS 1999), Although animal source foods are not absolutely essential to humans, including even small amounts in diets of malnourished individuals have proved to play a key role in improving nutritional status (Millward, 1999). 


\section{Important nutrients from animal source foods and human health}

Many diets in developing countries are deficient in the quantities of energy, protein and other nutrients compared with recommendations, but the quality of the sources of nutrients is also important (Layman, 2010). Dietary quality, or the ability of a given diet to provide all the required water, energy, protein, fatty acids, minerals, vitamins and fibre, is as significant as dietary quantity. In addition to how much food is consumed, the nutritional profile of this food should be considered when trying to improve the nutritional status of a population, or when dietary recommendations are made. Animal-based proteins contain greater amounts of protein per portion, and contain all the essential amino acids, but do not inhibit the absorption of other essential nutrients such as plant-based proteins. In addition, animal source foods contain bioavailable haem iron, which is more readily absorbed in the human body than iron from plant sources, similar to many other essential micronutrients. (Bioavailability of a nutrient refers to the proportion of the nutrient ingested that becomes absorbed and is available for bodily functions.)

\section{Protein}

According to the World Health Organization (WHO), dietary protein intake in developing countries falls significantly short of the recommended $0.66 \mathrm{~g} / \mathrm{kg}$ body weight per day (FAO, 2011). In these countries protein is obtained from staple foods that are mainly cereal based (Layman, 2010). These foods contain a lower quantity of protein than animal sources (Table 1), and are often low in the essential amino acids lysine, and tryptophan (Millward, 1999) and sulphur-containing amino acids, compromising the quality of the protein source (Bender, 1992). The quality of a protein source has a direct influence on protein digestibility, as a greater proportion of higher-quality proteins is absorbed and becomes available for bodily functions. Protein from animal sources is of high quantity and quality as it includes a full complement of the essential amino acids in the right proportions (Millward, 1999).

Table 1 Protein content of a serving of selected foods commonly consumed by South Africans (Wolmarans et al., 2010)

\begin{tabular}{llc}
\hline Food group & One Serving & Protein amount (g) \\
\hline \multirow{3}{*}{ Meat, chicken \& } & 85 g beef, lean cooked & 28 \\
fish & 85 g chicken, cooked & 26 \\
& 85 g sardines (pilchards) with bone & 21 \\
\hline \multirow{3}{*}{ Legumes } & 172 g (1 cup) cooked soybeans & 29 \\
& 196 g (1 cup) boiled split peas & 16 \\
& 256 g (1 cup) red kidney beans & 13 \\
\hline Egg & 50 g (1 large) boiled egg & 6 \\
\hline \multirow{3}{*}{ Dairy } & 245 g (1 cup) milk & 8 \\
& 28 g cheddar cheese & 7 \\
& 30 g low fat cottage cheese & 3 \\
\hline \multirow{3}{*}{ Starch \& cereals } & 158 g (1 cup) white rice, cooked & 4 \\
& 219 g (1 cup) oat bran & 7 \\
& 28 g (1 slice) whole wheat bread & 4 \\
\hline \multirow{2}{*}{ Vegetables \& fruit } & 180 g (1 cup) spinach & 5 \\
& 1 (118 g) banana & 1 \\
\hline
\end{tabular}

Research has shown that adding even small amounts of animal proteins to a plant-based diet can yield large improvements in maternal health and child development (Dagnelie et al., 1994; Neumann et al., 2003). Significant associations have been found between animal protein intake and lean mass, but no such association with vegetable protein intake has been reported. High-quality dietary protein, in combination 
with micronutrients provided by animal sources, facilitates body protein synthesis during growth and tissue repair after extreme physical activity, and assists in repairing and preserving muscle mass in elderly individuals, which postpones and treats sarcopenia (the degenerative loss of skeletal muscle mass, quality and strength associated with ageing) (Lord et al., 2007; Paddon-Jones \& Rasmussen, 2009).

\section{Beneficial fatty acids}

Fat is generally a valued element in the diet, which provides energy, acts as a carrier for the fat-soluble vitamins $\mathrm{A}, \mathrm{D}, \mathrm{E}$ and $\mathrm{K}$ as well as $\beta$-carotene, increases the palatability of dry foods, and serves as a cooking medium. Fat content differs significantly among animal source foods. In Table 2 the fat and fatty acid composition of various products are compared. Fillet is the leanest portion in beef (Schönfeldt et al., 2010), loin is the leanest portion in pork (Van Heerden et al., 2008), while leg is generally the leanest cut for lamb and mutton (Schönfeldt \& Hall, 2012). Breast is generally the leanest part of poultry meat. Skin is probably the main source of fat in poultry meat retail cuts (Wolmarans et al., 2010).

Originally, dietary fat was considered a source of energy. Later research introduced the concept of essential fats that need to be provided by the diet to prevent deficiencies. Two dietary fatty acids are classified as essential, namely linoleic acid (C18:2) and linolenic acid (C18:3). Research has also shown that fatty acids play a major role in preventing chronic conditions such as cardiovascular diseases. This has resulted in increased interest in the quality of the dietary lipid supply as a major determinant of long-term health and wellbeing (Uauy \& Kain, 2002).

The contribution of animal source foods to the supply of total fat and saturated fatty acids is well known, but their supply of dietary unsaturated fatty acids is less widely recognized. Overall, red meat contains similar proportions of monounsaturated fatty acids (MUFAs) and saturated fatty acids (SFAs), although the exact proportions of the fatty acids vary depending on its fat content. Lean meat is relatively higher in polyunsaturated fatty acids (PUFAs), and lower in SFAs and total fat than untrimmed meat. Meat and meat products contribute consistently to the diet not only in terms of essential fatty acids such as linoleic (C18:2n-6) acid and $\alpha$-linolenic (C18:3n-3) acid, but also eicosanoic acid (C20) and docosanoic acid (C22), polyunsaturated fatty acids present in meat phospholipids. Ruminant meats and oily fish are the only significant sources of preformed C20 and C22 PUFA in the diet (Enser et al., 1998; Wyness et al., 2011). Although human beings have the metabolic capacity to synthesize C20 and C22 fatty acids from the n-6 or $\mathrm{n}-3$ precursors of linoleic and $\alpha$-linolenic acid, respectively, an increase in the consumption of C20 and C22 n-3 polyunsaturated fatty acids could overcome the perceived imbalance in the ratio of n-6 : n-3 polyunsaturated fatty acids in modern diets. Omega-3 fatty acids have been shown in epidemiological and clinical trials to reduce the incidence of cardiovascular disease (Kris-Etherton et al., 2003). Large-scale epidemiological studies suggest that individuals at risk of coronary heart disease benefit from the consumption of plant-, animal- and marine-derived omega-3 fatty acids, although the ideal intakes are still unclear (Kris-Etherton et al., 2003).

Animal source foods have naturally occurring trans fats. Recent concern about the effects of trans fatty acids on the risk of coronary heart disease (CHD) has led many countries to implement strategies to reduce their consumption. However, the evidence across multiple geographical locations at normal levels of consumption indicates an inverse or no association between ruminant trans-fatty acid (rTFA) intake and CHD (Uauy et al., 2009; Gebauer et al., 2011). Therefore most recommendations currently require reductions in consumption of trans fatty acids from industrial hydrogenated fats (Enser et al., 1998; CraigSchmidt \& Rong, 2009; Gordon, 2013). Reducing intake of trans fatty acids from animal source foods, however, might lower the intake of other beneficial dietary components, including protein, vitamin $\mathrm{B}_{12}$, iron, calcium and zinc.

There has been considerable interest in conjugated linoleic acid (CLA) in recent years because of the effects of CLA isomers in human nutrition. CLA is probably the best known trans fatty acid found in meat and dairy products of ruminants. Biological synthesis of CLA occurs through the microbial isomerization of dietary linoleic acid in the digestive tracts of ruminants. The products from ruminant species are therefore rich dietary sources of CLA (Enser et al., 1998; Schmid et al., 2006; Gebauer et al., 2011). Rumenic acid 
Table 2 Comparison of fat content and lipid profile of edible portion of animal source foods (per $100 \mathrm{~g}$ raw edible portion)

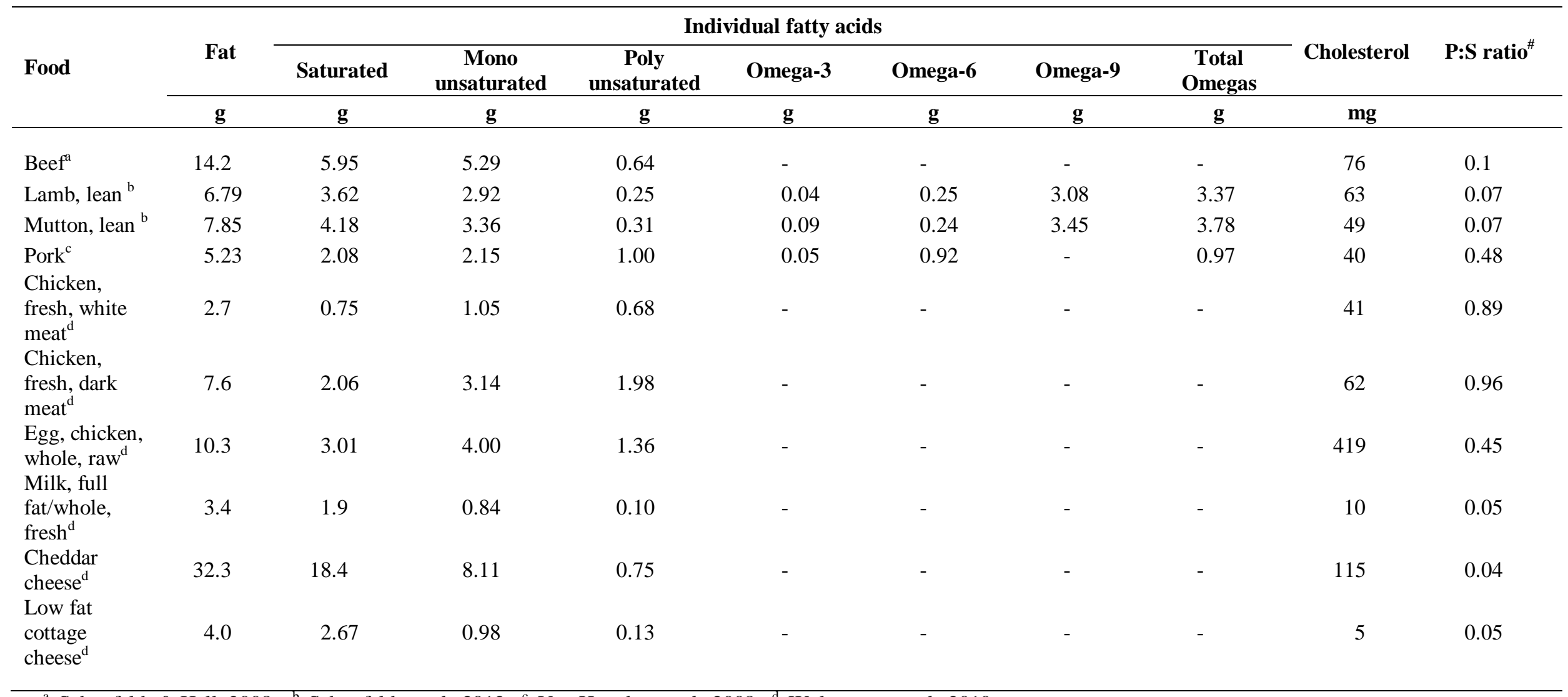

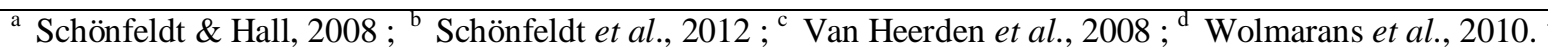

${ }^{\#} \mathrm{P}: \mathrm{S}$ ratio: polyunsaturated : saturated fatty acid ratio. 
(C18:2 c-9, t-11) is the main CLA component in milk, with vaccenic acid (C18:1t-11), the main monounsaturated trans fatty acid, being present at $46.5 \%$ of total trans fatty acids. Vaccenic acid can be desaturated to rumenic acid in the human body, thereby increasing the CLA available to tissues by a considerable amount above dietary intake (Gordon, 2013). Although animal studies have suggested that CLA may lower plasma cholesterol and triacylglycerol concentrations, most human studies have found no significant effect on plasma total, low-density lipoprotein (LDL) and high-density lipoprotein (HDL) cholesterol concentrations (Baer, 2012; Gordon, 2013). CLA was also found to have no significant effect in human beings on body weight or body weight regain after a weight loss programme. In addition, the evidence on the anti-carcinogenic effects is still not sufficiently convincing to allow a conclusion about the positive anti-carcinogenic effect of CLA (Gordon, 2013). More clinical studies are warranted owing to the limited number of studies and inconsistencies in the data in order to substantiate positive or negative claims regarding the health claims of rTFA and CLA.

\section{Micronutrients}

Many of the current policy programmes aimed at improving food security and nutrition promote a sustainable food-based approach to combat malnutrition (FAO, 2012). The nutrient levels in selected foods are presented in Table 3. Animal-based foods tend to be richer sources of nutrients of concern such as iron and zinc. Although the nutrient density of animal products provides ample reason to promote inclusion of these in optimal diets, the quality and bioavailability of specific nutrients of concern should be considered (Gibson, 1994; Welch \& Graham, 2005). According to the 1999 National Food Consumption Survey, the five most often consumed foods are maize porridge, brown bread, black tea, sugar and a small amount of full cream milk (NFCS, 1999). The naturally present fibres, phytates, oxalates and tannins in the three most often consumed foods may interfere with absorption of nutrients. Although essential minerals such as calcium, iron and zinc are present in cereals and vegetables, they have a lower bioavailability in plant-based foods than in animal source food sources, owing to their chemical form and the presence of inhibitors in the food source such as phytic acid, oxalic acid and dietary fibre. Many factors in a food influence the effects of a single nutrient in a food matrix and it is inaccurate to generalize about the effects of a single nutrient without considering the food in which it is present.

As an example, animal source foods and plant source foods contain different types of iron. Plant source foods such as spinach contain only non-haem iron, while animal source foods contain both haem and non-haem iron. The bioavailability of ingested iron differs significantly between the types of iron (haem or non-haem). In general, the rate of non-haem iron absorption is related to its solubility in the upper part of the small intestine. Thus the presence of soluble enhancers and inhibitors consumed during the same meal has a significant effect on the amount of non-haem iron absorbed. Haem iron is much less affected by other dietary factors and contributes significantly to absorbable iron. Animal source foods are considered good sources of the more bio-available haem iron (Pettit et al., 2011).

Calcium must be in a soluble form, generally ionized $\left(\mathrm{Ca}^{2+}\right)$, at least in the upper small intestine or bound to a soluble organic molecule before it can cross the wall of the intestine (Guéguen \& Pointillart, 2000). Several molecules in the diet make calcium soluble or keep it in solution in the ileum, in particular milk proteins such as the phospho-peptides derived from casein (Scholz-Arens \& Schrezenmeir, 2000) and amino acids such as L-lysine and L-arginine, which form soluble chelates with calcium. Lactose, lactic acid (Rasic, 1987) and other carbohydrates, which are more gradually absorbed, have an effect, but the mechanism is still a matter of controversy.

It is now generally agreed that lactose, at least in high doses (15\% - 30\%), increases the passive absorption of calcium (Guéguen \& Pointillart, 2000; Kwak et al., 2012). Other dietary factors make calcium irreversibly insoluble at near-neutral $\mathrm{pH}$ values, by converting it into forms such as oxalates (Heaney et al., 1988), phytates (Kärkkäinen et al., 1997) phosphates and soaps, which prevent passive absorption in the ileum (Guéguen \& Pointillart, 2000). The high level of calcium in dairy products plays a particularly important role in the development, strength and density of bones for children and in the prevention of osteoporosis in older people. In addition, calcium has been shown to be beneficial in reducing cholesterol absorption, and in controlling body weight and blood pressure (Gaucheron, 2013). 
Table 3 Composition of selected foods (per 100 g) compared with the Nutrient Reference Intake (NRV) for individuals four years and older

\begin{tabular}{|c|c|c|c|c|c|c|c|c|c|c|}
\hline Nutrient & Unit & $\begin{array}{c}\text { Fortified } \\
\text { maize } \\
\text { porridge, } \\
\text { stiff a }^{\text {a }} \\
\end{array}$ & $\begin{array}{c}\text { Fortified } \\
\text { brown bread }^{\text {a }}\end{array}$ & $\begin{array}{l}\text { Spinach, } \\
\text { boiled }^{\mathrm{a}}\end{array}$ & $\begin{array}{l}\text { Chicken } \\
\text { with skin } \\
\text { (frozen) }^{\text {boiled }} \\
\text { boil }^{\text {a }}\end{array}$ & $\begin{array}{c}\text { Egg, } \\
\text { chicken, } \\
\text { boiled }^{\mathrm{a}}\end{array}$ & $\begin{array}{l}\text { Beef, fillet, } \\
\text { cooked, } \\
\text { untrimmed }^{\mathrm{a}}\end{array}$ & $\begin{array}{c}\text { Cheese, } \\
\text { cottage, low } \\
\text { fat }^{\text {a }}\end{array}$ & $\begin{array}{c}\text { Lamb, loin, } \\
\text { cooked, } \\
\text { trimmed b }\end{array}$ & $\begin{array}{c}\text { Nutrient } \\
\text { Reference }^{\text {Intake }}\end{array}$ \\
\hline Energy & kj & 455 & 1029 & 134 & 923 & 616 & 803 & 369 & 761 & - \\
\hline Protein & g & 2.7 & 9 & 2.7 & 26.8 & 12.6 & 30.9 & 10.5 & 27.8 & 56 \\
\hline Fat & g & 0.6 & 1.4 & 0.3 & 12.6 & 10.3 & 7.5 & 4.0 & 7.8 & - \\
\hline Vitamin $B_{1}$ & $\mathrm{mg}$ & 0.13 & 0.46 & 0.02 & 0.08 & 0.11 & 0.24 & 0.04 & 0.12 & 1.2 \\
\hline Vitamin $B_{2}$ & $\mathrm{mg}$ & 0.05 & 0.11 & 0.07 & 0.15 & 0.38 & 0.19 & 0.21 & $0.22^{\mathrm{d}}$ & 1.3 \\
\hline Vitamin $\mathrm{B}_{6}$ & $\mathrm{mg}$ & 0.12 & 2.13 & 0.04 & 0.17 & 0.04 & 0.44 & 0.07 & $0.06^{\mathrm{d}}$ & 1.7 \\
\hline Vitamin $\mathrm{B}_{12}$ & $\mu \mathrm{g}$ & 0 & 0 & 0 & 0.3 & 1.6 & 2.3 & 0.7 & $1.60^{\mathrm{d}}$ & 2.4 \\
\hline Calcium & $\mathrm{mg}$ & 2 & 14 & 104 & 11 & 39 & 7.1 & 120 & $7.6^{\mathrm{d}}$ & 1300 \\
\hline Iron & $\mathrm{mg}$ & 1.3 & 4.1 & 2.2 & 0.8 & 1.8 & 2.5 & 0.6 & 2.87 & 18 \\
\hline Zinc & $\mathrm{mg}$ & 0.63 & 4.49 & 0.49 & 1.78 & 1.15 & 7.45 & 0.63 & 3.11 & 11 \\
\hline
\end{tabular}

${ }^{\mathrm{a}}$ Wolmarans et al., 2010; ${ }^{\mathrm{b}}$ Schönfeldt et al., 2012; ${ }^{\mathrm{D}}$ Department of Health, 2010; ${ }^{\mathrm{d}}$ Purchas \& Wilkinson, 2011. 
The high nutrient density of animal source food types has an advantage in food-based interventions targeting vulnerable groups such as infants, children and people living with HIV/AIDS, who may have difficulty in consuming the large volumes of plant based foods needed to meet their nutritional requirements (FAO, 2009b).

One hundred grams cooked beef provides almost an entire day's recommended intake of vitamin $\mathrm{B}_{12}$, and half of the recommended intake of protein and zinc, and contributes substantially to meeting the vitamin $B_{1}$, vitamin $B_{2}$, vitamin $B_{6}$ and iron recommendations. Similarly, two large eggs supply more than $20 \%$ of the daily protein requirements, nearly $30 \%$ of daily vitamin $B_{2}$ requirements and $66 \%$ of daily vitamin $B_{12}$ requirements (Table 4 ). A serving size (30 g) of cheddar cheese provides almost $20 \%$ of the daily calcium requirements, more than $10 \%$ of daily zinc requirements and $8 \%$ of daily vitamin $B_{2}$ and $B_{12}$ requirements.

Furthermore, animal source foods provide multiple micronutrients simultaneously, which may be important in diets that are marginally lacking in more than one nutrient. For example, vitamin A and riboflavin are needed for iron mobilization and haemoglobin synthesis, and iron supplements may not reduce the prevalence of anaemia if intakes of these other nutrients are low (Murphy \& Allen , 2003). Thus, foods such as liver that contain substantial levels of iron and preformed vitamin A may be more effective than single nutrient supplements in alleviating poor micronutrient status, emphasizing the delivery of nutrients within a specific food matrix. In addition, the bioavailability of carotenoids such as vitamin A precursors is now believed to be lower than indicated in traditional food composition tables (Scott \& Rodriquez-Amaya, 2000; Van Het Hof et al., 2000; Tang, 2010). Thus, for diets that depend on plant sources for provitamin A carotenoids, more fruits and vegetables are needed to meet vitamin A requirements than was previously thought. For vitamin $B_{12}$, all requirements must be met from animal source foods or supplementation, as there is virtually no vitamin $B_{12}$ in plant source foods (Murphy \& Allen, 2003).

\section{Animal source foods, over-nutrition and related health risks}

When populations modernize as a result of socio-economic development, urbanization and acculturation, this is often characterized by a nutrition transition - changes in dietary patterns and nutrient intakes that increase the risk of diet-related non-communicable diseases (Vorster et al., 2011). While some of the associated dietary changes improve calcium and iron intake as a result of higher dairy and meat consumption, the nutrition transition is also associated with increased consumption of saturated and total fat, sodium and added sugars. Intake of legumes and vegetables commonly decreases, while intake of micronutrient-poor snack foods, convenience foods (often high in sodium and fat) and sweetened carbonated beverages, as well as added sugar, increases (Chopra et al., 2002; Vorster, 2010).

\section{Over-nutrition in South Africa}

In addition to persistent nutritional deficiencies, the incidence of overweight and obesity is increasing. In 1999 nearly 10\% of South African children under nine years of age were recorded as overweight or obese, with 4\% being obese (NFCS, 1999). Of the adult population, in 1998 (SADHS, 1998) 29\% of men and 55\% of women were overweight, and $9 \%$ of men and $29 \%$ of women were obese. By $2003,56.2 \%$ of the total adult population were recorded as overweight or obese (SADHS, 2003). When findings from SANHANES-1 were compared with the 2003 South African Demographic and Health Survey (SADHS), the study showed that the percentage of people who were underweight or had normal weight had decreased; while those overweight or obese had increased. Some $19.6 \%$ of men and $25 \%$ of women were overweight, and $11.6 \%$ of men and $40.1 \%$ of women were obese (SANHANES-1, 2013b).

\section{Animal source foods and weight management}

Health problems associated with being overweight have escalated in the last 10 years, even in developing countries. Currently, overweight and obesity are linked to more deaths worldwide than underweight. Obesity, with its co-morbidities such as metabolic syndrome and cardiovascular diseases, is a growing public health concern around the world, with significant statistics reported for South Africans (SADHS, 2003; SANHANES-1, 2013b). To address this problem, it is imperative to identify treatment interventions that target a variety of short- and long-term mechanisms. An energy appropriate, nutrient-dense total diet that includes minimally processed and fibre-rich foods helps to support a healthy body weight 
throughout the lifecycle (McNeill \& Van Elswyk, 2012). Obesity is a complex disorder with a diverse range of causal factors, including metabolic traits (e.g. control of food selection) and behavioural ones (e.g. binge eating or limited physical activity) (Butland et al., 2007). One undeniable fact, however, is that for an individual to become obese, energy intake must be higher than energy expenditure for an extended period. This means that either more energy than needed is consumed or that too little energy is used by the body because of lack of physical activity. In general, weight gain seems to be a result of a combination of increased energy intake and decreased energy expenditure (Table 4).

Table 4 Energy intake and expenditure in relation to weight management (Schönfeldt \& Hall, 2012)

\begin{tabular}{ll}
\hline $\begin{array}{l}\text { Maintaining } \\
\text { weight }\end{array}$ & $\begin{array}{l}\text { In balance - energy consumed through food and drink is equal to energy spent } \\
\text { Gaining weight }\end{array}$ \\
$\begin{array}{l}\text { Energy excess - energy consumed is exceeding energy spent, and the body deposits excess energy } \\
\text { in fat storage cells }\end{array}$ \\
$\begin{array}{l}\text { Energy deficit - energy consumed is less than energy spent, thus the body is forced to burn fat in } \\
\text { storage cells as energy }\end{array}$
\end{tabular}

\section{Animal source foods, fat and weight management}

To lose weight, an energy deficit is required, either through an increased energy expenditure (increased physical activity) or a decrease in energy intake (controlled dietary consumption). Conventionally, fat intake is often limited in energy-controlled diets, as fat contributes more than double the kilojoules per gram compared with protein or carbohydrates. Because dietary fat is derived from a variety of sources, the fat content of the diet as a whole needs to be reduced. The target recommendation is that no more than $35 \%$ of total food energy (total kilojoules ingested) should be from fat (FAO, 2010).

Animal source foods contain high biological value protein and important micronutrients required for optimal body functioning, but are regarded as sources of fat that contribute to the intake of total fat and saturated fatty acids in the diet. As a result of consumer demand, the fat content of South African red meat has decreased to less than $10 \mathrm{~g}$ per $90 \mathrm{~g}$ portion through breeding, farming and butchering techniques (Schönfeldt et al., 2012).

Contrary to popular belief, lean red meat compares favourably in terms of fat content with other animal source foods including chicken with or without the skin (Table 5). It is important to maintain or reduce the fat content of the protein source. This can be done through choosing lean cuts, trimming visible fat (including skin) prior to consumption, and limiting the addition of fats or oils during cooking or basting. It is also important to keep within recommended portion size and spread protein intake throughout the day to increase the benefit of satiety derived from the protein and moderate fat content (Schönfeldt \& Hall, 2008). Satiety is defined as the sensation of fullness that persists after eating until hunger returns (Benelam, 2009).

\section{Animal source foods, protein and weight management}

In addition to controlling fat intake, there is ample evidence that diets that are restricted in carbohydrates and have a stronger emphasis on protein intake can aid weight loss (Paddon-Jones et al., 2008). Reasons that red meat may help decrease weight include the increased satiating properties of protein, which may explain decreased food intake (Benelam, 2009), as well as the effect that increased protein intake has on thermogenesis, body composition and decreased energy efficiency (Wyness et al., 2011).

There has been increased interest in manipulating satiety in order to control energy intake and body weight. Many studies have found that higher protein meals significantly increase satiety compared with low protein meals (1 to 24 hours) (Wyness et al., 2011). In general, in diets where energy intake is unrestricted, increased consumption of high protein foods has been associated with lower body weight (Halton \& Hu, 2004; Layman, 2010). 
Table 5 Fat content of trimmed (lean) and untrimmed animal products (Wolmarans et al., 2010; Schönfeldt et al., 2012)

\begin{tabular}{lc}
\hline Food (100 g, cooked) & Fat (g) \\
\hline Trimmed & 7.7 \\
Lamb, leg, roasted, lean & 7.8 \\
Lamb, loin, roasted, lean & 9.9 \\
Lamb, shoulder, braised, lean & 7.2 \\
Mutton, leg, roasted, lean & 9.8 \\
Mutton, loin, roasted, lean & 8.7 \\
Mutton, shoulder, braised, lean & 9.8 \\
Chicken, dark meat, roasted, without skin & 9.7 \\
Chicken, dark meat, boiled, without skin & 3.6 \\
Chicken, white meat, roasted, without skin & 4.1 \\
Chicken, white meat, boiled, without skin & 8.3 \\
Pork, loin, braised, lean & \\
Untrimmed & 25.4 \\
Pork, thick rib/breast, braised, untrimmed & 11.7 \\
Lamb, leg, roasted, untrimmed & 20.9 \\
Lamb, loin, roasted, untrimmed & 15.8 \\
Lamb, shoulder, braised, untrimmed & 10.1 \\
Mutton, leg, roasted, untrimmed & 25.4 \\
Mutton, loin, roasted, untrimmed & 11.3 \\
Mutton, shoulder, braised, untrimmed & 14.4 \\
Beef, rump, roasted, untrimmed & 18.0 \\
Beef, prime rib, roasted, untrimmed & 8.2 \\
Beef, shoulder, braised, untrimmed & 12.6 \\
Chicken, meat and skin, boiled & 13.0 \\
Chicken, meat and skin, roasted & 13.9 \\
Pork, loin, grilled, untrimmed & \\
\hline
\end{tabular}

A high intake of the amino acid, leucine, and providing more than $1.2 \mathrm{~g}$ protein $/ \mathrm{kg}$ body weight per day or a minimum of $30 \mathrm{~g}$ protein at each of three daily meals, has been shown to promote muscle health and long-term weight management (Layman, 2010). Adding even small amounts of animal protein to a plantbased diet can yield large improvements in maternal health and child development, because plant-based diets are often low in normally limited amino acids, including lysine and sulphur containing amino acids, methionine and cysteine. Recommended intakes for protein are presented in Table 6. Refer to Table 1 for the protein content per serving of food.

\section{Animal source foods and cancer}

More than $13 \%$ of all deaths globally are related to cancer, with approximately $70 \%$ (and rising) of all cancer deaths occurring in industrialised countries (WHO, 2012). The burden of cancer is increasing in developing countries, as childhood mortality declines and more people live to older ages while adopting western lifestyles, such as smoking, higher consumption of saturated fat and energy dense foods, and reduced physical activity (American Cancer Society, 2007). In South Africa 1 in 6 men have a lifetime risk of getting cancer, 1 in 23 of prostate cancer, 1 in 69 of lung cancer, 1 in 82 of oesophageal cancer, and 1 in 
97 of colorectal cancer (NHLS, 2012). One in eight women has a lifetime risk of cancer, with 1 in 29 of breast cancer, 1 in 35 of cervical cancer and 1 in 162 of colorectal cancers (NHLS, 2012).

Table 6 Recommended daily protein intake (g/kg body weight) per population group

\begin{tabular}{lc}
\hline Group & g protein per kg body weight per day \\
\hline Population average & 0.66 \\
Sedentary people & $0.8-1.0$ \\
Recreational exercisers & $0.8-1.0$ \\
Athletes in early phase of training & $1.5-1.7$ \\
Athletes in established programme & $1.0-1.2$ \\
Serious endurance athletes & $1.2-1.6$ \\
Adolescent athletes & $1.5-2.0$ \\
Female athletes & $15 \%$ less
\end{tabular}

A plethora of studies have investigated the association between environmental and lifestyle factors, including diet and the risk of cancer. The World Cancer Research Fund and the American Institute for Cancer Research (WCRF/AICR, 2007) describe changes in the rates of cancers in genetically identical populations that migrate from their native countries. Most changes are in line with urbanization and industrialization. In South Africa these changes often go hand in hand with acculturation from traditional cultures and habits to westernised cultures and habits. In South Africa, the population is increasingly moving towards higher living standards in more urbanized settings (BFAP, 2011).

Cancer, however, remains a disease of genes that are vulnerable to mutation, particularly over the increasing human lifespan (WCRF/AICR, 2007). Yet environmental factors have been proven to be the most important contributors to cancer development and can be modified. External factors include tobacco, chemicals, radiation, and infectious organisms, while internal factors include genetic mutations, hormones, immune conditions and metabolism mutations. Normally various factors act together or in sequence to initiate or promote carcinogenesis, and no single study can prove that any single factor is a cause of, or is protective against any specific type of cancer. Therefore, as listed in Table 7, risks should be considered against prevalence to provide insights.

Table 7 Most common risk factors for development of cancer

\begin{tabular}{ll}
\hline Ranking & Risk Factor \\
\hline 1 & Growing older \\
2 & Tobacco \\
3 & Sunlight \\
4 & Ionizing radiation \\
5 & Certain chemicals and other substances \\
6 & Some viruses and bacteria \\
7 & Certain hormones \\
8 & Family history of cancer \\
9 & Alcohol \\
10 & Poor diet, lack of physical activity, or being overweight \\
\hline
\end{tabular}


A critical review of thousands of epidemiological studies found that the available scientific evidence does not support an independent association between red meat or processed meat and cancer (Alexander et al., 2010). Any observed linkage between selected cancers and animal source foods is likely to be related to other westernised lifestyle factors, including obesity and low physical activity, increased consumption of refined foods, alcohol and smoking, and decreased consumption of vegetables and fruits.

\section{Animal source foods and hypertension (high blood pressure)}

Hypertension refers to the constant pumping of blood through the vessels with excessive force. As blood pressure (BP) rises to above $120 \mathrm{~mm} \mathrm{Hg}$ systolic and above $80 \mathrm{~mm} \mathrm{Hg}$ diastolic, the risk of cardiovascular disease (CVD) and stroke increases. BP levels are measured as systolic (the pressure in the vessels when the heart beats), and diastolic (the pressure in the vessels when the heart rests between beats).

Hypertension is considered one of the leading causes of death globally, resulting in $51 \%$ of deaths from stroke and $45 \%$ from coronary heart disease. Nearly 1 billion people have hypertension and the incidence is increasing, particularly in developing countries. By 2025, an estimated 1.56 billion people globally will probably be living with hypertension (WHO, 2011).

The most comprehensive estimates of the prevalence of hypertension in South Africa (SA) were reported by the Demographic and Health Survey (SADHS, 1998). According to this survey, 6 million adults suffered from hypertension with BP greater than 140/90 mm Hg. In 2005, the prevalence of hypertension was reported as $55 \%$ in adults, with $59 \%$ in black African adults, $55 \%$ in coloured and Indian adults, and $50 \%$ in white adults (Connor et al., 2005). With CVD ranked as one of the greatest contributors to death in the country (Bradshaw et al., 2000), it is no surprise that hypertension has been shown to constitute more than $7.5 \%$ of the total healthcare spend (Seedat \& Rayner, 2007).

Transition of households from rural to urban settings, often resulting in the adoption of westernised lifestyle and eating habits, has been reported to be accompanied by an increased incidence of hypertension (Steyn \& Temple, 2008). These urbanized individuals have been recorded to have higher body weight, and urinary sodium/potassium ratio than their rural counterparts. Other factors often associated with these urbanised subjects include high intakes of saturated fat and sodium, suggesting the significant impact that lifestyle and eating habits have on the risk of hypertension. However, an increasing risk of hypertension is not associated only with urbanization, as an increasing incidence has also been reported in rural areas (Steyn et al., 2006).

Dietary sodium is associated with elevated BP levels, with intakes recommended below 6 g per day. Although many reports suggest the low addition of salt during food preparation and at the table, hidden salt in food products contributes to a significant proportion of dietary sodium intake in South Africa (Carlton et al., 2005). Consumers should be aware of this, and read food labels. From sodium values reported on food labels, salt quantity can be calculated by multiplying sodium content with a factor of 2.5. Daily salt intakes for South Africans have been recorded at $7.8 \mathrm{~g} /$ day in the black population, $8.5 \mathrm{~g} /$ day in the coloured population and $9.5 \mathrm{~g} /$ day in the white population, all being significantly higher than the recommended 6 g/day. Ethnic differences in sodium intake have also been recorded, with the black population consuming significantly lower levels than the other population groups. The greatest contributors to sodium intake in South Africa are cereals and breads (Carlton et al., 2005).

Adequate consumption of dietary potassium lowers the risk of hypertension and stroke (D'Elia et al., 2011). It has been hypothesized that because of this functionality of potassium, populations that consume primitive and vegetarian diets often have a low incidence of hypertension and heart disease. Table 8 presents the sodium $(\mathrm{Na})$ and potassium $(\mathrm{K})$ content of certain foods consumed by South Africans.

Animal source foods contain inherently very little sodium. Sodium is often added to meat for a variety of reasons, including enhancement of sensory properties (taste), reducing water activity and increasing microbial safety. Many consumers add salt habitually. Consumer benefits associated with the reduction of salt, and particularly added salt, should be emphasised.

Processed meat products can be a significant contributor to dietary salt intake. The higher sodium levels in processed meats (not fresh or frozen red meat) could contribute to increased hypertension risk (McNeill \& Van Elswyk, 2012). This may explain the disparity in findings related to dietary patterns and risk 
of CVD. Processed meat and unprocessed red meat should therefore be grouped and investigated separately in future research studies.

Table 8 Sodium (Na) and potassium (K) content of selected South African foods (100 g edible portion) ${ }^{\#}$ (Wolmarans et al., 2010; Schönfeldt \& Hall, 2012)

\begin{tabular}{|c|c|c|}
\hline Food products & Na (mg) & K (mg) \\
\hline \multicolumn{3}{|l|}{ Meat \& meat products } \\
\hline Lamb, trimmed (lean) & $71^{*}$ & 288 \\
\hline Lamb, untrimmed & $61^{*}$ & 248 \\
\hline Mutton, trimmed (lean) & $73^{*}$ & 272 \\
\hline Mutton, untrimmed & $65^{*}$ & 243 \\
\hline Beef, untrimmed & $80^{*}$ & 282 \\
\hline Chicken, white meat, roasted & $48^{*}$ & 269 \\
\hline Chicken, dark meat, roasted & $73^{*}$ & 262 \\
\hline Fish, hake, steamed & $126^{*}$ & 361 \\
\hline Egg, whole, boiled & $126^{*}$ & 98 \\
\hline Vienna & 953 & 101 \\
\hline Sausage, smoked, beef and pork & 945 & 189 \\
\hline Sausage roll, commercial, baked & 1044 & 114 \\
\hline \multicolumn{3}{|l|}{ Dairy } \\
\hline Cheese, cheddar & 487 & 82 \\
\hline Milk, whole, fresh & 48 & 157 \\
\hline \multicolumn{3}{|l|}{ Vegetables \& fruit } \\
\hline Broccoli, boiled & $4^{*}$ & 121 \\
\hline Carrots, boiled & $29 *$ & 156 \\
\hline Potato, baked & $8^{*}$ & 418 \\
\hline Apple & 4 & 99 \\
\hline Banana & 41 & 206 \\
\hline Peach & 4 & 201 \\
\hline \multicolumn{3}{|l|}{ Cereals } \\
\hline Bread, brown, fortified & 648 & 227 \\
\hline Bread, white, fortified & 653 & 214 \\
\hline Maize, soft, fortified & $5^{*}$ & 24 \\
\hline Rice, white & $2 *$ & 39 \\
\hline Rice, brown & $5^{*}$ & 43 \\
\hline \multicolumn{3}{|l|}{ Condiments } \\
\hline Chutney, fruit & 811 & 25 \\
\hline Gravy, brown, powder, prepared with water & 417 & 22 \\
\hline Tomato sauce & 582 & 465 \\
\hline Soup, powder, onion & 8957 & 667 \\
\hline $\begin{array}{l}\text { Soup, powder, average, prepared with } \\
\text { water }\end{array}$ & 431 & 64 \\
\hline
\end{tabular}

\#Values are reported as per 100 g edible portion; portion sizes usually consumed should also be considered when giving dietary advice.

*No salt was added during cooking. 
Evidence supports the inclusion of lean red meat and dairy as part of a healthy and balanced diet designed to manage CVD and hypertension (McNeill \& Van Elswyk, 2012). The DASH (Dietary Approaches to Stop Hypertension) study proved that non-pharmacological methods can decrease blood pressure equal to the effect of certain medications (Appel et al., 1997). The Seventh Report of the Joint National Committee on Prevention, Detection, Evaluation and Treatment of Hypertension (NIH, 2003) recommended reducing weight, adopting a DASH eating plan, reducing dietary sodium, increasing physical activity and moderating alcohol consumption. The World Health Organization (WHO) recommended, in addition, increased consumption of dietary potassium as a possible dietary intervention to decrease risk of hypertension (WHO, 2005).

The South African Hypertension Guidelines 2011, published by the South African Hypertension Society (SAHS) also emphasize that a healthy lifestyle remains the cornerstone of managing hypertension, regardless of the BP level of the individual (Seedat \& Rayner, 2007). In addition to decreasing blood pressure, lifestyle changes enhance antihypertensive drug efficiency and decrease total CVD risk. These recommendations include maintaining a healthy body weight (BMI 18.5 to 24.9), reducing sodium intake to $<6$ g salt per day, limiting alcohol consumption, limiting fat intake to between $15 \%$ and $30 \%$ of total dietary energy intake and reducing SFA and TFA intakes, increasing fruit and vegetable consumption, limiting free sugars and increasing physical activity (Seedat \& Rayner, 2007).

\section{Nutrient density}

A healthy, balanced diet builds on the foundation of the right amounts of nutrient-dense foods from a variety of food groups, including lean meat, whole grains, vegetables, fruit and dairy products. The more nutrients present and the fewer the kilojoules, the higher the nutrient density. The term 'nutrient-rich foods' is usually used as a synonym for nutrient dense.

Animal source foods play a key role in a balanced diet by providing nutrients. A serving of lean red meat provides more than seven nutrients in significant amounts that are important to human health and development. A 90 g edible portion of lean South African lamb or mutton, that is, the meat from two lamb chops, contributes nearly half of an adult's recommended dietary allowance (RDA) for protein, more than $30 \%$ of the RDA for zinc and significantly to the intake of other essential vitamins and minerals including iron and magnesium, as well as the B vitamins.

\section{Portion size}

Apart from deciding what and when to eat, an important decision is how much to eat. Many health conscious consumers are perfectly capable of making healthy food choices for three wholesome meals per day, yet many people struggle with portion sizes. Most of the time we unknowingly eat portions that are too large and this contributes to an increased risk of overweight and obesity.

Over-sized portions of food have become the norm in many households. The portion sizes of takeaways, soft drinks and meals served at restaurants have increased over the last 20 years, often as a result of the increased demand for value for money. Unfortunately, portion sizes that were once considered far too big to consume in one sitting are now regarded as normal. Larger portions contain more kilojoules, and often the result is growing waistlines. Consuming three regular meals per day has also changed to constant grazing, with individuals losing track of what they are consuming throughout the day and over-consuming food.

The South African Food-Based Dietary Guidelines recommends up to 560 g lean red meat per week, between $80 \mathrm{~g}$ and $90 \mathrm{~g}$ per day. This is in line with the average consumption statistics for South Africans. However, it is well known that this range differs significantly from person to person. Cooking losses in meat are on average between 20\% and 30\% (Schönfeldt et al., 2012), depending on cut, composition (meat, bone and fat ratio), temperature of the heat source, internal temperature of cooked meat, added condiments, etc. This means that an $80 \mathrm{~g}$ cooked lean meat portion is roughly equivalent to $100 \mathrm{~g}$ raw lean meat.

\section{Conclusions and Recommendations}

There is consensus in international dietary recommendations that animal source foods form part of a healthy and balanced diet. Important nutrients provided by animal source foods include high-quality and bioavailable protein, beneficial fatty acids and essential, bioavailable micronutrients such as haem iron and 
calcium. These nutrients are important for their individual health benefits, but animal source foods can be useful as a food-based approach to combat persistent under-nutrition.

Unfortunately, animal source foods are often considered the most expensive components in the diet and evoke the widest array of comments and international debate. As such, it is often recommended that animal source foods should be limited in the human diet. Yet, ample evidence indicates that health concerns related to animal source food consumption (such as increased risk of weight gain, cancers and hypertension) are questionable, and evidence increasingly suggests a beneficial effect that animal source foods may have in preventing and controlling obesity and certain NCDs.

In addition, there is a dearth of recent food consumption data that describes the contribution that animal source foods make to the South African diet. Prior to such data being available, caution should be used when sanctions are made to reduce intake, as intake may be below the recommended amounts of the Food-Based Dietary Guidelines. Animal source foods are seldom consumed on their own, but form part of a whole meal. The composition of the rest of the meal should not be neglected when healthy food choices are made. Certain nutritional considerations, such as nutrient density and portion size, should be applied to all foods included in the diet.

Investment in research for example describing animal source food consumption, health properties, and nutrient composition is essential to address consumer concerns and position animal source foods accurately as part of a healthy, sustainable diet.

\section{References}

Alexander, D.D., 2010. Red meat and processed meat consumption and cancer: A Technical summary of the epidemiologic evidence. Health Sciences Practice, Exponent, Inc.

American Cancer Society, 2007. Global Cancer Facts \& Figures. [Online] Available at: www.cansa.org.za/cause_data/ images/1056/Research_-_Global_Facts_\&_Figures_2007.pdf [Accessed August 2012].

Appel, L.J., Moore, T.J. \& Obarzanek, E., 1997. A clinical trail of the effects of dietary patterns on blood pressure. New Eng. J. Med. 336, 1117-1124.

Arsenos, G., Zygoyjannis, D., Kufidis, D., Katsaounis, N. \& Stamataris, C., 2000. The effect of breed slaughter weight and nutritional management of cholesterol content of lamb carcasses. Small Rumin. Res. 36, 275-283.

Astrup, A., Dyerberg, J., Elwood, P., Hermansen, K., Hu, F.B., Jakobsen, M.U., Kok, F.J., Krauss, R.M., Lecerf, J.M., LeGrand, P., Nestel, P., Risérus, R., Sanders, T., Sinclair, A., Stender, S., Tholstrup, T. \& Willet, W.C., 2011. The role of reducing intakes of saturated fat in the prevention of cardiovascular disease: where does the evidence standin 2010? Am. J. Clin. Nutr. 93, 684-688.

Baer, D.J., 2012. What do we really know about the health effects of natural sources of trans fatty acids? Am. J. Clin. Nutr. 95, 267-268.

Bender, A., 1992. Meat and meat products in human nutrition in developing countries, Rome: Food and Agricultural Organisation.

Benelam, B., 2009. Satiation, satiety and their effects on eating behaviour. Nutr. Bull. Vol. 34, 126-173.

BFAP, 2011. Bureau for Food and Agricultural Policy: The South African Agricultural Baseline. [Online] Available at: www.bfap.co.za [Accessed June 2013].

Bognár, A., 2002. Tables on weight yield of food and the retention factors of food constituents for the calculation of nutrient composition of cooked foods (dishes). Berichte der Bundesforschungsanstalt für Ernährung, Karlsruhe. ISN 0933-5463.

Bradshaw, D., Masiteng, K. \& Nannan, N., 2000. Health status and determinants. South African health review. pp. 89-124.

Butland, B., Jebb, S. \& Kopelman, P., 2007. Foresight Tackling Obesities - Future Choices - Project Report., London: Government Office for Science, Department of Innovation.

Carlton, K.E., Steyn, K. \& Levitt, N.S., 2005. Diet and blood pressure in South Africa: intake of foods containing sodium, potassium, calcium and magnesium in three ethnic groups. Appl. Nutr. Invest. 21, 39-50.

Chopra, M., Galbraith, S. \& Darnton-Hill, I., 2002. A global response to a global problem: the epidemic of over-nutrition. Bulletin of the World Health Organisation 80, 952-958. 
Connor, M.D., Walker, R. \& Modi, G., 2005. Chronic disease of lifestyle technical report. Chronic Diseases of Lifestyle Unit, Medical Research Council, PO Box 19070, Tygerberg 7505.

Craig-Schmidt, M.C. \& Rong, Y., 2009. Evolution of world-wide consumption of trans fatty acids. In: Trans Fatty Acids in Human Nutrition. Eds: Destaillats, F., Sebedio, J., Dionisi, F. \& Chardigny, J., 2nd ed. Bridgwater: The Oily Press, P.J. Barnes \& Associates. pp. 329-380.

DAFF, 2012. Abstract of Agricultural Statistics, Pretoria: Directorate Statistics and Economic Analysis, Department of Agriculture, Forestry and Fisheries.

Dagnelie, P.C., Van Dusseldorp, M., Van Staveren, W.A. \& Hautvast, J.G., 1994. Effects of macrobiotic diets on linear growth in infants and children until 10 years of age. EJCN. 48, p. S103-S111.

Del Vecchio, A., Ancel Keys, A. \& Anderson, J.T., 1955. Concentration and distribution of cholesterol in muscle and adipose tissue. Proc. Soc. Exp. Biol. Med. 90, 449-451.

D'Elia, L., Barba, G. \& Cappuccio, F., 2011. Potassium intake, stroke and cardiovascular disease: A metaanalysis of prospective studies. J. Am. Coll. Cardiol. 57, 1210-1219.

Department of Health, 2010. Foodstuffs, Cosmetics and Disinfectants Act, 1972 (Act no 54 of 1972), Regulation R 146 (dated 1 March 2010), regulations relating to the labelling and advertising of foodstuffs, Pretoria: Government Gazette, South Africa.

Du Toit, D.C., Ramonyai, M.D., Lubbe, P.A. \& Ntushelo, V., 2011. Food Security, Pretoria: Directorate of Agriculture, Forestry, Fisheries, Private Bag X250, Pretoria, 0001. South Africa.

Enser, M., Hallett, K.G., Hewet, B., Fursay, G.A.J., Wood, J.D. \& Harrington, G., 1998. Fatty acid content and composition of UK beef and lamb muscle in relation to production system and implications for human nutrition. Meat Sci. 49, 329-341.

FAO, 2004. The state of food insecurity in the world 2004: monitoring progress towards the World Food Summit and Millenium Development Goals, Rome: Food and Agricultural Orginisation.

FAO, 2009a. Agribusiness Handbook - Red Meat. Rome: Food and Agricultural Organisation.

FAO, 2009b. Chapter 3: Livestock, food security and poverty. In: The State of Food and Agriculture. Rome: Food and Agricultural Organisation of the United Nations.

FAO, 2011. Dietary protein Quality evaluation in human nutrition. Report of an FAO Expert Consultation. 31 March - 2 April, Auckland, New Zealand. FAO Food and Nutrition Paper 92, Rome: Food and Agricultural Organisation.

FAO, 2012. Food and Argicultural Organisation's special programme for food security. [Online] Available at: http://www.fao.org/spfs/en[Accessed 15 July 2013].

FAOSTAT, 2013. South Africa Country Overview. [Online] Available at: http://faostat.fao.org [Accessed 25 June 2013].

Gaucheron, F., 2013. Milk minerals, trace elements, and macroelements. (Chapter 9) In: Milk and Dairy Products in Human Nutrition: Production, Composition and Health. Eds: Park, Y.W. \& Haenlein, G.F.W., First Edition. John Wiley \& Sons. pp. 172-199.

Gebauer, S.K., Chardigny, J-M., Jakobsen, M.U., Lamarche, B., Lock, A.L., Proctor, S.D. \& Baer, D.J., 2011. Effects of ruminant trans fatty acids on cardiovascular disease and cancer: A comprehensive review of epidemiological, clinical, and mechanistic studies. Adv. Nutr. 2, 332-354.

Gibson, R.S., 1994. Content and bioavailability of trace elements in vegeterian diets. Am. J. Clin. Nutr. 59, 1223S-1232S.

Gordon, M.H., 2013. Milk Lipids. (Chapter 4) In: Milk and Dairy Products in Human Nutrition: Production, Composition and Health. (First ed.). Eds: Park, Y.W. \& Haenlein, G.F.W., Edited by Park, Y.W., John Wiley \& Sons, Ltd, pp. 65-79.

Guéguen, L. \& Pointillart, A., 2000. The bioavailability of dietary calcium. J. Am. Coll. Nutr. 19, 119S$136 \mathrm{~S}$.

Halton, T.L. \& Hu, F.B., 2004. The effects of high protein diets on thermogenesis, satiety and weight loss: A critical review. J. Am. Coll. Nutr. 23, 373-385.

Heaney, R.P., Weaver, C.M. \& Recker, R.R., 1988. Calcium absorbability from spinach. Am. J. Clin. Nutr. 47, 707-709.

Iversen, P.O., Du PLessis, L., Marais, D., Morseth, M., Høisæther, E.A. \& Herselman, M., 2011. Nutritional health of young children in South Africa over the first 16 years of democracy. SAJCN. 5 (3), 72-77. 
Joubert, J., Norman, R., Bradshaw, D., Goedecke, J.H., Steyn, N.P. and the South African risk assessment \& collaborating group, 2007. Estimating the burden of disease attributable to excess body weight in South Africa in 2000. SAMJ. 97 (8), 683-690.

Kärkkäinen, M.U.M., Wiersma, J.W. \& Lamberg-Allardt, J.E., 1997. Postprandial parathyroid hormone response to four calcium-rich foodstuffs. Am. J. Clin. Nutr. 65, 1726-1730.

Kimani-Murage, E.W., Kahn, K., Pettifor, J.M., Tollman, S.M., Dunger, D.B., Xavier, F., Gómez-Olivé, X.F. \& Norris, S.A., 2010. The prevalence of stunting, overweight and obesity, and metabolic disease risk in rural South African Children. BMC Public Health, Volume 10, p. 158.

Kris-Etherton, P.M., Harris, W.S. \& Appel, L.J., 2003. Fish consumption, fish oil, omega-3 fatty acids and cardiovascular disease. Arterioscl. Throm. Vas. 20, 20-31.

Kwak, H.-S., Lee, W.-J. \& Lee, M.-R., 2012. Revisiting lactose as an enhancer of calcium absorption. Int. Dairy J. 22, 147-151.

Lanigan, J. \& Singhal, A., 2009. Early nutrition and long-term health: a practical approach. Proc. Nutr. Soc. 61, 422-429.

Layman, D., 2010. The changing roles and understanding about dietary protein for life-long health., pa KUlife.

Lord, C., Chaput, J.P., Aubertin-Lehuedre, M., Labonté \& Dionne, I.J., 2007. Dietary animal protein intake: association with muscle mass index in older women. J. Nutr. Health Aging 11 (5), 383-387.

McNeill, S. \& Van Elswyk, M.E., 2012. Red meat in global nutrition. Meat Sci. 92, 166-173.

Millward, D., 1999. Meat or wheat for the next millenium? Proc. Nutr. Soc. 58, 209-2011.

Murphy, S.P. \& Allen, L.H., 2003. Nutritional importance of animal source foods. J. Nutr. 133, 3932S3935S.

Neumann, C.G. et al., 2003. Animal source foods improve dietary quality, micronutrient status, growth and cognitive function in Kenyan school children: Background, study design and baseline findings. J. Nutr. 133, 3941S-3949S.

NFCS, 1999. The National Food Consumption Survey: children aged 1-9 years, South Africa, 1999, Pretoria: Department of Health, Nutrition Directorate, South Africa..

NFCS-FB-I, 2008. Executive Summary of the National Food Consumption Survey Fortification Baseline I: South Africa. SAJCN. 21 (3) (Suppl 2), 245-300.

NHLS, 2012. National Cancer Registry, National Health Laboratory Service.

NIH, 2003. The 7th Report on the Joint National Committee on prevention, detection, evaluation and treatment of high blood pressure. National Institute of Health, US Department of Health and Human Services.

Norman, R., Bradshaw, D., Schneider, M., Joubert, J., Groenewald, P., Lewin, S., Steyn, K., Vos, T., Laubscher, R., Nannan, N., Nojilana, B. \& Pieterse, D., 2007. A comparative risk assessment for South Africa in 2000: towards promoting health and preventing disease. SAMJ. 97 (8), 637-641.

Paddon-Jones, D., Westman, E. \& Matt, R.D., 2008. Protein, weight management, and satiety. Am. J. Clin. Nutr. 87 (S), 1558S-1561S.

Paddon-Jones, D. \& Rasmussen, B.B., 2009. Dietary protein recommendations and the prevention of Sarcopenia: Protein, amino acid metabolism and therapy. Curr. Opin. Clin. Nutr. 12 (1), 86-90.

Pettit, K., Rowley, J. \& Brown, N., 2011. Iron deficiency. Paediatr. Child Health 21 (8), 339-343.

Pinstrup-Andersen, P., 2007. Agricultural research and policy for better health and nutritionin developing countries: A food-systems approach. Agric. Econ. 37 (S1), 189-198.

POST, 2006. Food security in developing countries. London: Parliamentary Office of Science and Technology, Millbank.

Purchas, R.W. \& Wilkinson, B.H.P., 2011. The concentration of selected nutrients in New Zealand beef and lamb cuts and offal items, Institute of Food, Nutrition and Health, Massey University, Palmerston North, New Zealand.

Rasic, J.L., 1987. Nutritive value of yoghurt. Cultured Dairy Products, Volume August, pp. 6-9.

SADHS, 1998. South Africa Demographic and Health Survey, Pretoria: Department of Health, South Africa.

SADHS, 2003. South Africa Demographic and Health Survey, Pretoria: Department of Health, South Africa.

SANHANES-1, 2013a. The South African National Health And Nutrition Examination Survey, Media Release 2. Nutritional status of children. [Online] Available at: 
http://www.hsrc.ac.za/uploads/pageContent/3895/02\%20NUTRITIONAL\%20STATUS\%20OF\%20C HILDREN.pdf [Accessed 7 August 2013].

SANHANES-1, 2013b. The South African National Health And Nutrition Examination Survey, Media Release 1. Non-communicable diseases (NCDs). [Online] Available at: http://www.hsrc.ac.za/uploads/pageContent/3895/01\%20NONCOMMUNICABLE\%20DISEASES.pdf [Accessed 7 August 2013].

SAVACG, 1996. Anthropometric, vitamin A, iron, and immunisation coverage status in children aged 6-71 months in South Africa, 1994. SAMJ. 86, 354-357.

Schmid, A., Collomb, M., Sieber, R. \& Bee, G., 2006. Conjucated linoleic acid in meat and meat products: A review. Meat Sci. 73, 29-41.

Scholz-Arens, K.E. \& Schrezenmeir, J., 2000. Effects of bioactive substances in milk on mineral and trace element metabolism with special reference to casein phosphopeptides. BJN, 84 (Suppl. 1), S147-S153.

Schönfeldt, H.C. \& Hall, N., 2008. Changes in the nutrient quality of meat in an obesity context. Meat Sci. 80, 20-27.

Schönfeldt, H.C. \& Strydom, P.E., 2011. Effect of age and cut on cooking loss, juiciness and flavour of South African beef. Meat Sci. 87, 180-190.

Schönfeldt, H.C. \& Hall, N., 2012. Red meat in nutrition and health. (First ed.). Pretoria: University of Pretoria.

Schönfeldt, H.C., Hall, N. \& Van Heerden, S.M., 2012. The nutrient content of South African lamb and mutton. Menlo Park: Lamb and Mutton South Africa.

Schönfeldt, H.C., Naudé, R.T. \& Boshoff, E., 2010. Effect of age and cut on the nutritional content of South African beef. Meat Sci. 86, 674-683.

Scott, K.J. \& Rodriquez-Amaya, D., 2000. Pro-vitamin A carotenoid conversion factors: retinol equivalents fact or fiction? Food Chem. 69, 125-127.

Seedat, Y.K. \& Rayner, B.L., 2007. Impact of poverty on hypertension and cardiovascular disease in subsaharan Africa. Cardiovasc. J. Afr. 18, 316-320.

StatsSA, 2012. Income and expenditure survey (IES) 2010/2011. Statistics South Africa Press release. [Online] Available at:

http://www.statssa.gov.za/news_archive/press_statements/IES_\%202010_2011_Press\%20Statement_6 _November_2012.pdf [Accessed 12 July 2013].

Steyn, K., Fourie, J. \& Temple, N., 2006. Chronic diseases of lifestyle in South Africa: 1995 - 2005, Chronic Diseases of Lifestyle Unit, Medical Research Council, PO BOX 19070, Tygerberg 7505 ISBN: 1-920014-40-3.

Steyn, N.P. \& Temple, N., 2008. Community based nutrition textbook for South Africa: A right based approach. Cape Town: South African Medical Research Council FAO/MRC 101-160.

Tang, G., 2010. Bioconversion of dietary provitamin A carotenoids in humans. Am. J. Clin. Nutr. 91, 1468S$1473 S$.

Uauy, R., Aro, A., Clarke, R., Ghafoorunissa, L’Abbé, M.R., Mozaffarian, D., Skeaff, C.M., Stender, S. \& Tavel, M., 2009. WHO scientific update on trans fatty acids: summary and conclusions. EJCN. 63, S68-S75.

Uauy, R. \& Kain, J., 2002. The epidemiological transition: need to incoporate obesity prevention into nutrition programmes. Pub. Health Nutr. 5 (1A), 223-229.

USDA, n.d. National Nutrient Database for Standard Reference, Release 24. [Online] Available at: https://www.ars.usda.gov/SP2UserFiles/Place/12354500/Data/SR24/nutrlist/sr24a203.pdf [Accessed 12 July 2012].

Van Heerden, S.M. \& Smith, M.F., 2013. The nutrient composition of three cuts obtained from p-class South African pork carcasses. Food Chem. 140 (3), 458-65. doi: 10.1016/j.foodchem.2012.10.066.

Van Heerden, I.V., Schönfeldt, H.C. \& Hall, N., 2012. Literature survey to determine the intakes of 'food derived from animals' by the South African population in the period 2000 to 2010. Pretoria: Red Meat Research and Development South Africa, PO Box 35207, Menlo Park, 0102.

Van Het Hof, K.H., West, C.E., Weststrate, J.A. \& Hautvast, J.G., 2000. Dietary factors that affect the bioavailability of carotenoids. J. Nutr. 130, 503-506. 
Vorster, H.H., 2010. The link between poverty and malnutrition: A South African perspective. Health SA Gesondheid, pp. Art \#435, 6 pages.

Vorster, H.H., Kruger, A. \& Margetts, B.M., 2011. The nutrition transition in Africa: Can it be steered in a more positive direction? Nutrients 3 (4), 429-441.

WCRF/AICR, 1997. Food, Nutrition, Physical Activity and the prevention of Cancer, Washington, D.C.: World Cancer Research Fund \& American Institute for Cancer Research.

WCRF/AICR, 2007. Food, Nutrition, Physical Activity and the prevention of cancer. A global perspective, Washington, D.C.: World Cancer Research Fund \& American Institute of Cancer Research.

Welch, R.M. \& Graham, R.D., 2005. Agriculture: The real nexus for enhancing bioavailable micronutrients in food crops. J. Trace Elem. Med. Biol. 18, 299-307.

WHO, 2007. Protein and Amino Acid Requirements in Human Nutrition. Report of a Joint WHO/FAO/UNU Expert Consultation, Rome: World Health Organisation Technical Report Series no 935.

WHO, 2011. Hypertension - Fact Sheet, Rome, Italy: World Health Organization.

WHO, 2012. Cancer: Fact Sheet No 297, Rome, Italy: World Health Organization.

Wolmarans, P., 2010. Condensed Food Composition Tables for South Africa. Cape Town: Medical Research Council, South Africa.

Wyness, L., Weichselbaum, E., O'Connor, A., Williams, E.B., Benelam, B., Riley, H. \& Stanner, S., 2011. Red meat in the diet: An update. Nutr. Bull. 36, 34-77. 